\title{
Organizational climate enhance service quality through enhancing $O C B$ in public hospital.
}

\author{
Indahwaty Sidin*, Nur Arifah, Rifa'ah Mahmuda \\ Department of Hospital Management, Faculty of Public Health, Hasanuddin University, Makassar, Indonesia
}

\begin{abstract}
Purpose: For years, research has focused on organizational culture though the organizational climate $(O C)$ is a multidimensional construct. Hospital is a unique organization having unique climate, special for public hospital. This research was a quantitative study, a cross-sectional approach. The sample selected from 150 the employee of public hospitals in Makassar. The data was analyzed by structural equation model (SEM) to test the model of relationship among OC, OCB and SQ. The hypotheses were: 1) There was a relationship of $O C$ to $O C B$; 2) There was a relationship between $O C B$ and Service quality (SQ); 3) There was a relationship between $\mathrm{OC}$ and SQ.

Findings: The Confirmatory Factor Analysis (CFA) test presented the loading factor of managerial tools $<0,5$ means invalid indicator. The goodness of fit indicators showed the RMSEA 0,061 (fit). The model was accepted to be continued with structural model analysis. However, all hypotheses was rejected, $P$ values $>0,005$. The conclusion is $O C$ did not have role in increasing $O C B$ and $S Q$ in public hospital, Makassar. The structural model have to be modified.

Research limitations: The sample size was less than 200 and some indicators were invalid. Further research was supposed to apply other dimension of organizational climate and increase the sample size. Originality: The low OCB did not influence employee on providing service quality in public hospital in Indonesia since providing service quality is a mandatory from government.
\end{abstract}

Keywords: Organizational climate, Organizational citizenship behaviour, Service quality.

Accepted on July 12, 2019

\section{Introduction}

For years, research has focused on organizational culture compare to organizational climate [1]. Though the organizational climate (OC) is a multidimensional construct between organizational culture and employee perceptions about the organization. Research on OC shows that conflicts in the work life of employees are intermediaries in creating an organizational climate in work place [2]. OC influences employee morale and organizational commitment $[3,4]$. Therefore, it is important to create favourable climate in the workplace by increasing employee job satisfaction, creativity, motivation and retention. Good OC will trigger the emergence of good morale from employees, loyalty, and increased productivity [5].Likewise the individual's psychological status, it will certainly affect the way they act, so that their perceptions will influence the way they made decisions.

Furthermore, Organizational culture can be reflected from philosophy of organization founders, leader in organization, share value and believe of dominant culture of organization members, and country. Indonesia has unique culture and hospital has unique culture as well. It employs mixture professions, such as doctors, nurses, pharmacist, etc. This fact may result in different perception of organizational climate. In addition, it is influenced by organizational context, organizational practice, belief, value, and role of top management [6]. The organizational context is related to organizational goals, size, resources, and technology. Whereas organizational practice includes the policies and procedures in organization.

Organizational types will certainly influence policies, procedures and regulations, so that private organizations have a different climate from public organizations. In Indonesia, hospitals managed by the private sector are certainly not too rigid to follow government regulations, for example in financial management and employee recruitment. Of course this will lead to different cultures which in turn give different organizational climate impacts. Public hospitals tend to have petty bureaucratic compared to private hospitals.

Moreover, different organization's missions can lead to differences in organizational culture which will further create a different organizational climate. Likewise with organizational types and organizational ownership. Public hospitals may have a different mission from private hospitals, thus lead to different organizational culture. Research conducted at one of the public hospitals in Tusca, Italy shows that employees have different 
perceptions of the organizational climate based on the mission and ownership status of the hospital [7]

OC which may have impact on OCB. Some studies explain that there are several antecedent factors towards the manifest of OCB, one of which is the organizational climate. Other studies found that there was a positive and significant relationship between organizational commitment and organizational climate [3].

Furthermore, The high OCB of employees reflect the high commitment of employees to produce the best performance so that the quality of services provided can exceed customer expectations. OCB's contribution to quality services (QS) has a limited concept and empirical support [8-10]. Health care is a growing sector which has received a lot of attention from researchers and doctors worldwide and that requires a lot of consideration due to the deficiencies that the sector have and challenges to overcome as a result of competition between public and private sectors.

For this reason, this study was conducted to explain the role of organizational climate in increasing service quality through enhancing OCB at public hospital in Makassar, Indonesia.

\section{Literature Review}

\section{Organizational climate}

The concept of organizational climate was introduced in the late 1930 s by Levine et al. Organizational climate is an attribute and characteristic that is understood by employees and reflected through actions, processes, and relationships between people in the organization and environment. Organizational climate is one of the main concepts in organizational behaviour that can help to create innovation and inspiration in the organization so that it will ultimately have a positive effect on achieving organizational goals [3].

Organizational climate is a characteristic that describes an organization and (a) distinguishes one organization from another, (b) persists, (c) influencing the behaviour of people in the organization [11].

Organizational climate tends to be oriented towards conditions that can create creativity, innovation, safety, or service, for example in the workplace [12]. In short, the organizational climate can be interpreted as people's interaction through a number of experiences held in the workplace [13]

From the various definitions, it can be concluded that the organizational climate is a perception formed from various experiences in the organization that are realized in the form of actions and relationships between employees and the environment in where they work. A favourable climate makes employees behave positively so that they can help achieve organizational goals.

In measuring organizational climate, there are some dimension developed, Litwin and Stringer [14] developed an instrument known as Litwin and Stringer Organizational Climate
Questionnaire (LSOCQ). This instrument consists of 9 (nine) scales which then become organizational climate dimensions [15] namely structure, responsibility, reward, risk, warmth, support, standard, conflict, and identity. But over time these dimensions grew and increased in number.

Another dimension used by Rojas et al. [7], the right dimension to measure organizational climate in health service organizations consists of 5 (five) dimensions:

- Managerial tools, is budget allocations used to regulate organizations.

- Training opportunities is an opportunity given to employees to develop their potential by participating in education or training that is useful for the progress of the organization.

- Communication and information processing organizations, is a process of providing information to employees regarding matters that occur within the organization.

- Management and leadership, is a routine activity and requires interaction between superiors to achieve organizational goals.

- Job satisfaction is the job satisfaction experienced by employees in the workplace so that employees feel happy and proud to be able to work in that place.

\section{Organizational citizenship behaviour}

According to Organ OCB is defined as free work behaviour (voluntary), not related to a system of rewards in formal organizations and is a unit that can improve organizational effectiveness. Employees who have OCB can make the organization go beyond the required and expected performance indicators. OCB is a representation of activities carried out informally because employees feel satisfied with their work and get fair treatment [16]. Without OCB, the organization will continue to run because employees continue to work on their main tasks, but everything that runs in the organization will be rigid and has become a fixed procedure. OCB is not an action that has the potential to get reprimand or punishment, because this behaviour can actually increase organizational effectiveness.

Smith et al. and Organ [16,17] uses five dimensions as a factor that determines employee OCB. The five factors include altruism, conscientiousness, courtesy, civic virtue, and sportsmanship. Furthermore, Williams and Anderson [18] then divided the five dimensions into two categories, namely OCBOrganization (OCB-O) consisting of the civic virtue and sportsmanship and OCB-Individual (OCB-I) dimensions consisting of dimensions of altruism, conscientiousness, and courtesy.

OCB-O is a behaviour that is beneficial to the organization in general such as providing information or take permission to superiors when they unable to attend work, this refers to informal behaviours that are not required to be done. Whereas OCB-I is a behaviour that provides specific benefits to individuals and this indirectly also contributes to the organization. For example by helping to complete the work of 
a colleague who is absent on that day, and mutual respect for each other at work Williams and Anderson [18].

The five OCB dimensions of the Organ and the measurement scale from Podsakoff were the most widely used in OCB literature to date. The five OCB dimensions are explained in more detail as follows Chahal and Mehta [19]: a) Altruism, means the principle of prioritizing others. Altruism refers to voluntary behaviour. Altruism is voluntary behaviour that occurs when a person supports another employee in completing his duties under unusual conditions Organ, [16]. Altruism is the willingness to provide assistance to others. Altruism can be interpreted as giving help to other people who need help, so that problems or difficulties faced can be resolved; b)Courtesy, interpreted as honour or kindness. Courtesy refers to behaviour that is directed at preventing future problems. Courtesy is the behaviour of helping someone to prevent a problem from occurring, or acting in front to reduce the problem behind (Organ [16] Courtesy is different from altruism, in the sense that altruism focuses on helping someone who has a problem, while coutesy helps to prevent problems, gives wise considerations to others [20]; c) Sportsmanship, It emphasizes the positive aspects of negative organizations. In other words, sportsmanship refers to the behaviour of individuals who are tolerant to disturbances that cannot be avoided in the workplace. Sportsmanship is a set of behaviours that show tolerance for deficiencies of ideal conditions in the workplace without complaints [21]; d) Conscientiousness, interpreted as conscience. This term refers to timely behaviour, high attendance rates, and beyond normal requirements or expectations. In other words, conscientiousness refers to someone who does his job (in-role behaviour) who meets the level above the minimum required standard and refers to being more careful and listening to the inner voice; e) Civic virtue, is citizenship awareness. This term includes support for administrative functions of the organization. Civic virtue consists of behaviours that care about the political life of the organization, such as attending meetings, engaging in policy debates, and expressing opinions in implementing new policies.

Based on various research results, it can be explained that OCB cannot formed just like that, but based on something that is a factor in the emergence of OCB. The emergence of OCB behaviour is influenced by various very complex factors. Organ [22] suggested several factors that influence OCB including culture and organizational climate, personality and mood, perceptions of organizational support, perceptions of the quality of interaction between subordinate superiors (LeadersMember Exchange), years of service, and gender.

\section{Service quality (SQ)}

The definition of service quality is various among experts. Some experts define service quality is based on customer expectation, other experts define service quality means fulfill standards,. According to Japanese Philosophy, service quality is similar to zero defects. Parasuraman et al. [22] stated Service quality described as a form of attitude related but not equivalent to satisfaction, the results from the comparison of expectation performance.

Zeithaml et al. [22,23] stated that there are five types of elements in assessing the quality of hospital services, namely:

- Reliability, these assessment indicators include hospital administration service procedures, regular employee incentive payments, staff providing services with a friendly attitude, providing training opportunities for employees to improve their competence, providing updated information, and every policy related to employees is always socialized.

- Assurance, the assessment indicators include employees who always get friendly service from fellow employees, employees receive services from competent staff, and hospitals always update their employees' knowledge and skills.

- Tangible (Physical Evidence), the assessment indicators include the appearance of employees who are always welldressed and polite in carrying out their duties, worship facilities for employees, canteens, and a safe and comfortable work environment.

- Empathy (Concern), the assessment indicators are that the hospital gives attention to grieving employees, employees get help from superiors/fellow employees if there is difficulty in work, and hospitality that is always maintained between employees.

- Responsiveness, the indicator of the assessment is that the employee gives a good and quick response to the patient's complaints and suggestions as well as a quick response to the wishes of the patient.

\section{Materials and Methods}

\section{Study setting}

The study was undertaken in Makassar, a one of big city in Indonesia. It involves 3 (three) public hospitals.

\section{Design and sampling}

The research type is a quantitative study with a cross-sectional approach. The population were all public hospitals employees in Makassar which numbered 2,967 employees. Study used a simple random sampling technique; the sample size in this study was calculated based on known populations. It was 150 sample selected from 3(three) public hospital. According to Loehlin [24] and Hoyle [25], regard to SEM analysis, if research model consisting 2-4 variables then it was needed 100-200 samples. This study analysed 3 variables so the number sample size was appropriate for estimating structural equation model. The hypotheses tested in this study include: 1) There were relationship between Organizational Citizenship Behaviour (OCB) and Service quality (SQ); 2) There were relationship of Organizational climate (OC) to OCB; 3) There were relationship between OC and SQ 


\section{Questionnaire and data collection}

Questionnaires were used to collect data from sample. Validity test has been applied to all the questionnaires through SPSS. It was developed based on its dimension. OCB dimension were altruism, conscientiousness, courtesy, civic virtue, and sportsmanship Organ [16], then OC dimension are managerial tools, training opportunity, organization, and management and leadership [13]. As for OCB and OC questionnaires, respondents asked to answer questions which reflect their behaviour in a daily working. The answers were divided into four choices based on Likert scale (1-4). As for quality services, the dimension used were reliability, assurance, tangible, empathy and responsiveness [22]. The respondents asked to choose answer based on their opinion. The choices were divided into 5 categories, strongly disagree, normal, agree, and strongly agree. The questionnaires were administered using a face-to-face approach by researchers. If the respondent did not understand the questionnaires, The researchers explained

\section{Analysis}

Since this study measured the relationship of 3 (three) variable, one of them was a mediator variable, then the data was analyzed by multivariate analysis second generation. The structural equation model (SEM) this study tested the model relationship of OC and QS with OCB as a mediator [26-28]. The analysis of study consisting two sections. First section was basic univariate analysis for respondent characteristics and the research variable. Aside from basic descriptive analyses, the second analytic techniques were Structural Equation Modeling to confirm theory based on research data.

This study conducted CB SEM analysis consisted 4 steps: 1) model specification, the conceptual construct was defined through theoretical meaning (Figure 1)

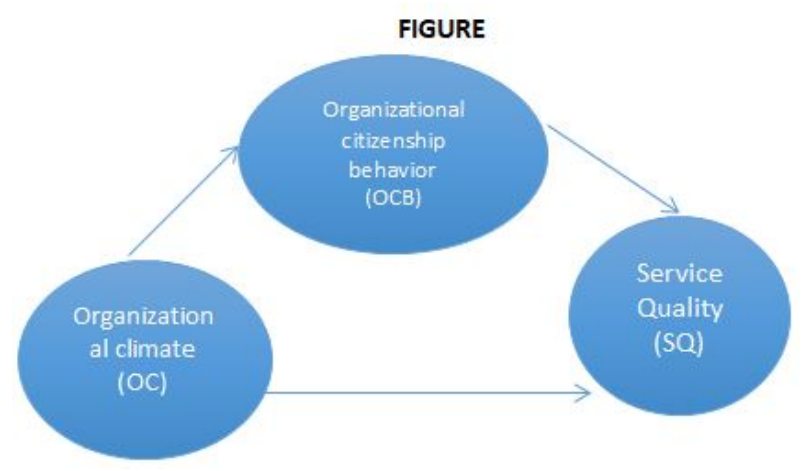

Figure 1. The conceptual model of relationship $O C B, O C$ and $S Q$.

Source: Modification the theory of Organ and George and Bettenhausen, 1990

2) Model estimation was used in this study was maximum likelihood;3)Model evaluation run into two stages. The first evaluation was for evaluating measurement model through confirmatory factor analysis (CFA). The purpose was to test validity and reliability of latent construct. The validity of variable was identified from the loading factor value (LFV), the construct must have LFV $>0,5$. Second stage is evaluation the structural model to detect significance $\mathrm{P}$-value, $\mathrm{R}$ squares and the overall fit model. The following indicators of $\mathrm{R}$ squares: 0,25 the model was strong; 0,45 the model was moderate ; 0,6 the model was weak. In addition, If the Goodness of fit was bad, the model have to be rejected and to be modiflied. The were some fit model measurements. This study used probability, GFI, AGFI, TLI, CFI, and RMSEA. The most popular fit measurement was RMSEA because it was not depend on sample size.4)Model Modification, this step was for identifying the percentage of variance for each variable through asses the R-squares, multi colinearity and P-value.

\section{Results}

\section{The respondents characteristics}

The characteristics of respondents are laid out below to give an overall description of their identity in this research. The characteristics are classified based on age, sex, and length of employment.

It can be seen from the Table 1, respondents within the adult category were dominating with $73.4 \%$ respectively, and it was also shows that female respondents were dominating with $83.2 \%$ respectively. The proportion of respondents having the length of employment about 1-5 years was almost similar to more than 10 years with about $35 \%$ of the total respondents.

Table 1. Characteristics of respondents.

\begin{tabular}{|c|c|c|c|}
\hline No & Respondent Characteristics & Total & $\%$ \\
\hline \multirow{4}{*}{1} & Age & & \\
\hline & Teenager ( $\leq 25$ years) & 12 & 8.4 \\
\hline & Adult (26-45 year) & 105 & 734 \\
\hline & elderly (46-65 years) & 26 & 26 \\
\hline \multirow{4}{*}{2} & Sex & & \\
\hline & Male & 24 & 16.8 \\
\hline & Female & 119 & 83.2 \\
\hline & Length of Employment & & \\
\hline \multirow{4}{*}{3} & $<1$ year & 1 & 7 \\
\hline & $1-5$ year & 53 & 37.1 \\
\hline & $6-10$ year & 40 & 28 \\
\hline & $>10$ year & 49 & 34.3 \\
\hline Total & & 143 & 100 \\
\hline
\end{tabular}

\section{Univariate analysis of variable}

Organizational Citizenship Behaviour Variable (OCB)

Organizational Citizenship Behaviour (OCB) was an employee's behaviour regard extra-role in working place 
without the expectation of receiving rewards in the event of increasing organizations effectively.

The result of frequency test using SPSS shows that most of the respondents have a high OCB $(91.6 \%)$ as shown in Table 2.

Table 2. Responses distribution on organizational citizenship behaviour.

\begin{tabular}{llll}
\hline No & Category & N & $\%$ \\
\hline 1 & Low & 12 & 81.4 \\
\hline 2 & High & 131 & 91.6 \\
\hline Total & & 143 & 100 \\
\hline
\end{tabular}

\section{Organizational climate variable}

OC Variable could be interpreted as a hospital employee's perception on the condition that takes place and is felt in the working place. Data on the above table showed that $56.6 \%$ of the respondents in government hospitals assumed that the organizational climate in his workplace is unsupportive (Table 3).

Table 3. Frequency distribution on organizational C climate hospitals year 2018

\begin{tabular}{llll}
\hline No. & Category & N & $\%$ \\
\hline 1 & Supportive & 62 & 43.4 \\
\hline 2 & Unsupportive & 81 & 56.6 \\
\hline Total & & 143 & 100 \\
\hline
\end{tabular}

\section{Service quality}

Quality Service could be interpreted as a service that is given by employee which fulfils customer expectation. Data on the Table 4 shows that most of the respondents be it in public hospital provided good quality ( $91.6 \%$ respectively).

\begin{tabular}{llll}
\hline No. & Category & N & $\%$ \\
1 & Low & 12 & 8.4 \\
2 & Good & 131 & 91.6 \\
Total & & 143 & 100 \\
\hline
\end{tabular}

Table 4. Response distribution on quality service public hospitals in Makassar.

\section{Multivariate analysis}

This analysis was to test and estimate simultaneously the relationship multiple latent variables to some indicators. Also, it was to test non-linear model. The first step of the analysis was to evaluate the measurement model through CFA. For testing the validity and reliability latent construct. The following Figure showed the LFV factor of three variables.
The Figure 2 has shown the loading factor value (LFV) of each latent variable. The value indicated how many score of indicator would be escalated if the variable increased 1 point. This figure revealed that increasing 1 point of $\mathrm{OC}$ result in escalating 0.14 managerial tools. Training opportunity will be escalated sharply ( 0.86 respectively) if OC was a rose 1 point. It means, the training opportunity had a dominant role in constructing the OC. As for OCB variable, the dominant factor was courtesy with the highest loading factor ( 0.81 respectively) among other indicators. Furthermore, the highest loading factor value of Qs indicator was assurance (0.87).

Figure 2. The CFA analysis of $O C, O C B$ and $S Q$.

The LFC determined the validity of the indicators to construct the variable latent. It was needed LFV about $0.5-0.7$ to denote the validity of indicator. However, there was 1 (one) indicator of $\mathrm{OC}$ having lower value than 0.5 ,it was managerial tools. This indicator means invalid to construct OC. The following model showed the assessment of overall fit model (Figure 3)

Figure 3. The structural model of $O C, O C B$ and $S Q$.

Table 5. The value of Goodness of Fit the measurement model.

\begin{tabular}{llll}
\hline Goodness of Fit & Value & Standard & Information \\
\hline Chi Square & 113.575 & & \\
\hline Probabilities & 0.002 & $\geq 0.05$ & Unfit \\
\hline GFI & 0,630 & $\geq 0.90$ & Fit \\
\hline AGFI & 0,60 & $\geq 0.90$ & Unfit \\
\hline TLI & 0,65 & $\geq 0.90$ & Fit \\
\hline CFI & 0,66 & $\geq 0.95$ & Fit \\
\hline RMSEA & 0.061 & $\leq 0.08$ & Fit \\
\hline
\end{tabular}

The Table 5 revealed that the measurement model was accepted. Then, the evaluation of structural model can be continued. This further evaluation was to recognize significance P-value, R-squares for exogenous variable and overall fit model. Hypothesis was tested to find the influence of exogenous variable on endogenous variable. The hypotheses would be accepted if probabilities value (P-value) $<0,05$. The next Table 6 showed the test result.

Tabel 6. The result test of Hyphothesis.

\begin{tabular}{ccccccc}
\hline & & & Estimate & S.E. & C.R. & P \\
\hline $\mathrm{OCB}$ & $<---$ & OC & 0.016 & 0.026 & 0.621 & 0.535 \\
\hline $\mathrm{SQ}$ & $<---$ & OC & -4.898 & 3.663 & -1.337 & 0.181 \\
\hline $\mathrm{SQ}$ & $<---$ & OCB & 0.361 & 0.227 & 1.589 & 0.112 \\
\hline
\end{tabular}

\section{Discussion and Implications}

The purpose of this study was to recognize the role of OC in increasing QS through enhancing OCB performance. This assumption was developed from some articles reviewing the 
relationship between OC and OCB. (2) Found that organizational commitment can be enhanced through providing supportive organizational climate. Organizational commitment is a result of the high performance of OCB. Furthermore, the OCB performance have influence on the high quality of service $[29,30]$

\section{The influence of organizational climate on organizational citizenship behaviour}

Organizational climate was defined as staff's perception of working environment. Other definition of OC was the process of people interaction in working place through their experience [13]. Every organization may have different climate and it can control people behaviour in organization[11] Favourable climate can enhance their commitment, improve innovation and cultivate innovation as they are satisfied with the working condition then provided high quality of services [31]; Perry et al. [32]. Some researchers developed the dimension of organizational climate. They stated that organizational climate can be assessed through the organization clarity, the organization support and the organization challenge [33]. Another climate dimensions were developed by Tuscan Health care organization. The dimensions consisted managerial tools, training opportunity, organization, Management and leadership [7].

However, the CFA test revealed that managerial tools were invalid indicator for organizational climate. This fact may occur due to the question of indicators did not reflect managerial tools. Budget responsibilities and controlling were small parts of managerial tools. According to Rigby and Bilodeau [34], there were 25 management tools used by managers to growth their organization, such as benchmarking, balanced score card, big data analysis, strategic planning, etc. However, OC was expression of as psychological climate, perceptual phenomena involving experience. Consequently, OC cannot be an aspect of organization or task structure as Koys and DeCotiis [35]. This statement disagrees with Rojas et al. [7]. Applying Tuscan dimension of organizational climate. This dimension applied organization aspect to measure organizational climate, such as managerial tools, training opportunity, organization and management and leadership. Although other expert stated that OC reflects staff perception about organization, in terms of practice, procedures, policies, routine and rewards(Barbera [36]; Schneider [37]; Rentsch [38]; Jones and James [39], budgeting and controlling involving managerial tools is unlikely to describe procedure, practice, policies, routine and rewards in organization.

Therefore, indicators of managerial tools were invalid statically, and most of respondents perceived unsupportive OC. The dimension of OC still needs more discussion.

Nevertheless, in this study, the data showed that most of respondents have high OCB, it can cause most of nurse had altruism because of their nature work. Nurse is a profession who intended to care and to help people. If they do not have empathy to help other people, they may not choose nurse profession

This study cannot prove that OC have role in increasing OCB. This result is congruent to other research done by Qadeer and Jaffrey[40], they found that the performance of OCB can be created if organizational climate supperted by psychological capital like and Walker et al. (2010). the impact of organizational climate on OCB is not direct; it is mediated by psychological capital, then OCB occurs only if supportive organizational climate is supported by psychological capital employee. It was related to staff ability to have self-efficacy and hope, be optimistic and resilience(Walumbwa et al. [41]; Norman et al. [42]; Luthans et al. [43]. The following Figure 4 denoted the finding of Qadeer and Jaffrey [40].

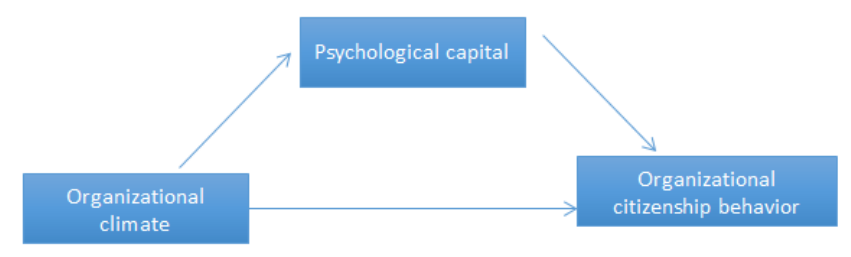

Figure 4. Denoted the finding of Qadeer and Jaffrey [40].

It was different finding from Gholami et al. [44] The findings revealed that there was a significant positive relationship between organizational climate and it's characteristics with Organizational Citizenship behaviour. Social capital, loyalty, entrepreneurship, knowledge sharing may be enhanced in organization when the employee perceive favourbale organizational climate, then OCB performance will increase.

Nevertheless, the empirical study at public hospital in makassar reflected that psychological capital may have a mediator role in increasing OCB. It is needed further research and discussion

\section{The influence of organizational citizenship behaviour (OCB) on service quality (SQ)}

This study asked employee as hospital internal customers to describe their perception on service quality.

OCB reflects the high commitment of employee and a representation of activities carried out informally because employees feel satisfied with their work and get fair treatment Organ [29] the employee doing the job passionately

Bienstock et al. [45] found that employee with OCB put their energy to increase organization performance. They always behave altruism means willingness to helping others to solve their problem, not only for staff but also for customers; Employee having consciousness refer to the high performance of their in role; Civic virtue is behaviour in related to willingness to participate in organization events, such as meeting, socialization. As a result, they increase awareness and knowledge regarding service quality. Disturbance always obvious in organization, it reflects dynamic organization, not all disturbance have to worry, but some employee may get in trouble because this disturbance. Staff having sportsmanship 
will show tolerance with this disturbance, they still do their in role even extra role. Not only this behaves, employee with courtesy always tries to do risk management, they tries to prevent the future proble [17]. All these behaviours result in more effective service delivery to fulfill organizational standards and enhance customer perceptions of service quality.

Service quality is more related to personal interaction, intangible aspect, thus employee behaviour and attitude determine how provided services quality (Parasuraman et al. [22]; Schneider and Bowen [46] Customer oriented behaviour may lead to provide service quality, only employee have OCB can conduct this behaviour in Particular in Hospital, most of customer (patient and family) going to hospital need more attention since they are unhealthy, sensitive and under pressure. The service in hospital is such a complex service, variability demand from patient [8].

Conversely, this study statistically did not show the relationship OCB between service quality, even though the univariate analysis showed that most of respondents had high OCB and most of them perceived hospital provided good quality services. This fact can be caused 2 factors. First factor, some indicators were invalid to measure the observable variable. Additionally, this result be caused by the small size of sample (150 respectively). Though Hoyle [47] stated that to predict a model, it is recommended 100-200 sample and Loehlin [48] indicated that study developing model of 2-4 variable, 100-200 sample is adequate, Bentler and Chou [9] specified the required sample based on the estimated parameter, every parameter required 5 sample. Moreover, Byrne [26] recommended minimum 500 sample for abnormal data. However, this data did not have normal distribution, accordingly, the 200 sample weaken the statistical analysis.

Second factor, providing service quality in public hospital was compulsory. All public hospital should be accredited by National Institution Accreditation for Hospital (KARS), otherwise the hospital will not get operational license from government and The hospital can not collaborate with National health Insurance. In fact, the government has universal coverage Program (UU SJSN $<$ UU RS, BPJS). This policies forces staff employee to provide good quality health service, even though they may not have OCB.

\section{The influence of organizational climate on service quality}

Service quality can be provided by satisfy employee. OC is one of antecedents of satisfy employee. Some empirical study has proved the role of organizational climate on employee satisfaction (Johnson and McIntye [49]; Tsai [50]; Avram et al. [51]. Moreover, satisfied employee will have passion to provide service quality. Their commitment to organization enhance result in high quality performance. As explained previously, to produce high quality services [52-54].

\section{Limitation}

However, this study has certain limitations. Firstly, the size of sample. It is needed big sample size to test the developed model through structural Equation Model (SEM).Secondly, some indicators of latent variable was invalid. The chosen dimension measure the organizational climate was unlikely to be appropriate. It is suggested to choose other dimension of organizational climate reflected psychological capital.

\section{Conclusion}

Although this study did not prove the role of organizational climate in increasing service quality through enhancing Organizational citizenship behaviour, there are some notes that the model should be modified, it is needed to measure psychological capital as a mediator variable of the relationship between $\mathrm{OC}$ and OCB.

\section{References}

1. Iljins J, Skvarciany V, Gaile-Sarkane E. Impact of organizational culture on organizational climate during the process of change. Procedia Soc Behav Sci 2015; 213: 944-950.

2. Spanuth T, Wald A. Understanding the antecedents of organizational commitment in the context of temporary organizations: An empirical study. Scand J Manag 2017; 33: 129-138.

3. Bahrami MA, Barati O, Ghoroghchian MS, Montazeralfaraj R, Ezzatabadi MR. Role of organizational climate in organizational commitment: The case of teaching hospitals. Osong Public Health Res Perspect 2016; 7: 96-100.

4. Permarupan PY, Saufi RA, Kasim RSR, Balakrishnan BKPD. The Impact of Organizational Climate on Employee' s Work Passion and Organizational Commitment. Procedia Soc Behav Sci 2013; 107: 88-95

5. Nair R. Climate studies and associated best practices to improve climate issues in the workplace. Women in Engineering ProActive Network. 2006

6. Ostroff C, Bowen DE. Moving HR to a higher level: HR practices and organizational effectiveness 2000.

7. Rojas D, Seghieri C, Nuti S. Organizational climate: Comparing private and public hospitals within professional roles. Suma de Negocios 2014; 5: 10-14.

8. Bell SJ, Menguc B. The employee-organization relationship, organizational citizenship behaviours, and superior service quality. J Retailing 2002; 78: 131-146

9. Bentler PM, Chou CP. Practical issues in structural modeling. Sociological Methods and Research 1987; 16: 78-117

10. Bettencourt LA, Brown SW. Contact employees: Relationships among workplace fairness, job satisfaction and prosocial service behaviours. J retailing 1997; 73: 39-61 
11. Forehand GA, Von Haller G. Environmental variation in studies of organizational behaviour. Psychological Bulletin 1964; 62: 361 .

12. Patterson MG, West MA, Shackleton VJ, Dawson JF, Lawthom R, Maitlis S, Robinson DL, Wallace AM. Validating the organizational climate measure: Links to managerial practices, productivity and innovation. J Organiz Behav 2005; 26: 379-408.

13. Schneider B, Ehrhart MG, Macey WH. Organizational climate and culture. Annu Rev Psychol 2013; 64: 361-388.

14. Litwin GH, Stringer RA. Motivation and Organizational Climate.

15. Rogers ED, Miles JWG, Biggs WD. The factor replicability of the Litwin and Stringer organizational climate questionnaire: an inter and intra-organizational assessment. J Manag 1980; 6: 65-78.

16. Organ DW. Organizational Citizenship behaviour. In J D B T-I E of the S. and B. S. (Second E. Wright, ed. Oxford: Elsevier 2015: 317-321.

17. Smith CA, Organ DW, Near JP. Organizational citizenship behaviour: Its nature and antecedents. J Appl Psychol 1983; 68: 653

18. Williams LJ, Anderson SE. Job satisfaction and organizational commitment as predictors of organizational citizenship and in-role behaviours. J Manag 1991; 17: 601617.

19. Chahal H, Mehta S. Antecedents and consequences of organisational citizenship behaviour (OCB): A conceptual framework in reference to health care sector. J of Ser Res 2010; 10: 25.

20. Podsakoff PM, Mackenzie SB, Moorman Rh, Fetter R. Transformational leader behaviours and their effects on followers' trust in leader, satisfaction, and organizational citizenship behaviours. Leadersh Q 1990; 1: 107-142.

21. Organ DW. Personality and organizational citizenship behaviour. J Manag 1994; 20: 465-478.

22. Parasuraman A, Zeithaml VA, Berry LL. A conceptual model of service quality and its implications for future research. J Market 1985: 41-50.

23. Parasuraman A, Zeithaml VA, Berry LL. Servqual: A multiple-item scale for measuring consumer perc. J Retail 1988; 64: 12.

24. Loehlin JC. Latent variable models: An introduction to factor, path, and structural analysis. Lawrence Erlbaum Associates, Inc; 1987.

25. Hoyle RH. Structural equation modeling: Concepts, issues, and applications. Sage; 1995 Feb 28.

26. Byrne BM. Structural equation modeling with AMOS: Basic concepts, Applications, and Programming. Mahwah, New Jersey. 2001.

27. Garson G, 2012. Structural Equation Modeling, Statistical Associates Publishing.

28. Latan H. Model Persamaan Struktural Teori dan Implementasi AMOS 21.0. Bandung: Alfabeta. 2013.
29. Morrison EW. Organizational citizenship behaviour as a critical link between HRM practices and service quality. Human Resource Management 1996; 35: 493-512.

30. Van Maanen J, Schein EH. Toward theory of organizational socialization. In: BM Staw (ed) Research in Organizational Behaviour 1979;1.

31. Shanker R, Bhanugopan R, Van der Heijden BIJM, Farrell M. Organizational climate for innovation and organizational performance: The mediating effect of innovative work behaviour. J Vocat Behav 2017; 100: 6777.

32. Perry C, May NL, Rodway G, Tracy A, Galer J. Validating a work group climate assessment tool for improving the performance of public health organizations. Hum Resour Health 2005; 3: 10.

33. Chahal H. Antecedents and consequences of organisational citizenship behaviour (OCB): A conceptual framework in reference to health care sector. J Ser Res 2010; 10: 25-24.

34. Rigby D, Bilodeau B. Management tools and trends 2011. London: Bain and Company 2011.

35. Koys DJ, DeCotiis TA. Inductive measures of psychological climate. Human Relations 1991; 44: 265-285.

36. Barbera KM. The Oxford handbook of organizational climate and culture. Oxford University Press; 2014.

37. Schneider B. The climate for service: An application of the climate construct. Organizational Climate and Culture 1990; 1: 383-412.

38. Rentsch JR. Climate and culture: Interaction and qualitative differences in organizational meanings. J App Psych 1990; 75: 668.

39. Jones AP, James LR. Psychological climate: Dimensions and relationships of individual and aggregated work environment perceptions. Organizational Behaviour and Human Performance 1979; 23: 201-250.

40. Qadeer F, Jaffrey H. Mediation of Psychological Capital between Organizational Climate and Organizational Citizenship behaviour 2014; 8: 453-470.

41. Walumbwa FO, Peterson SJ, Avolio BJ, Hartnell CA. An investigation of the relationships among leader and follower psychological capital, service climate, and job performance. Pers Psychol 2010; 63: 937-963

42. Norman SM, Avey JB, Nimnicht JL, Graber Pigeon N. The interactive effects of psychological capital and organizational identity on employee organizational citizenship and deviance behaviours. J Leadersh Organ Stud 2010;17:380-391.

43. Luthans F, Avolio BJ, Avey JB, Norman SM. Positive psychological capital: Measurement and relationship with performance and satisfaction. Pers Psycho 2007; 60: 541-572.

44. Gholami S, Keykale MS, Tir M, Ramandi FD, Karimi M, Rajaee R. Investigation the relationship between organizational climate and organizational citizenship behaviour among staff in hospital. Eur J Biol Med Sci Res 2015; 3: 54-63. 
45. Bienstock CC, DeMoranville CW, Smith RK. Organizational citizenship behaviour and service quality. J Ser Mark 2003; 17: 357-378.

46. Schneider B, Bowen DE. Personnel/human resources management in the service sector. Research in Personnel and Human Resources Management 1992; 10: 1-30.

47. Hoyle RH. Structural equation modeling: Concepts, issues, and applications. Sage; 1995 Feb 28.

48. Loehlin JC. Latent variable models: An introduction to factor, path, and structural analysis. Lawrence Erlbaum Associates, Inc; 1987

49. Johnson JJ, McIntye CL. Organizational culture and climate correlates of job satisfaction. Psychological Reports 1998; 82: 843-850.

50. Tsai C. The Organizational Climate and Employees ' Job Satisfaction in the Terminal Operation Context of Kaohsiung Port * G. The Asian Journal of Shipping and Logistics 2014; 30: 373-392.

51. Avram E, Ionescu D, Mincu CL. Perceived safety climate and organizational trust: the mediator role of job satisfaction. Procedia Soc Behav Sci 2015; 187: 679-684.
52. Kelley SW, Hoffman KD. An investigation of positive affect, prosocial behaviours and service quality. J Retailing 1997; 73: 407-427.

53. Li N, Chiaburu DS, Kirkman BL. Cross-level influences of empowering leadership on citizenship behaviour: Organizational support climate as a double-edged sword. J Management 2017; 43: 1076-1102.

54. Riad L. Assessing the Impact of Organisational Climate on Employees Commitment 2016; 7: 357-364.

\section{*Correspondence to}

\section{Indahwaty Sidin}

Department of Hospital Management

Faculty of Public Health

Universitas Hasanuddin

Makassar, Indonesia 